\title{
A Comparative Study of Physical Properties Using VARIOUS GRADES ASPHALT BINDER WITH DIFFERENT TYPE OF FIBERS
}

\author{
Sady A. Tayh ${ }^{\mathbf{a}, *}$, Rana A. Yousif ${ }^{\mathbf{b}}$, and Qais S. Banyhussan ${ }^{\mathbf{a}}$ \\ a Highway and Transportation Engineering Department, Faculty of \\ Engineering, Mustansiriyah University, Baghdad, Iraq \\ b Highway and Transportation Engineering Department, Faculty of Engineering, Mustansiriyah \\ University, Baghdad, Iraq
}

\begin{abstract}
For a long time, bitumen has been utilized as the essential material for asphalt pavement construction. The factors of increasing axle loads, increasing traffic movement, critical climate conditions and many forms failures in construction have steered many researchers to seek some methods to enhance the asphalt binder properties. Even though various types of modifiers have been utilized in strengthening asphalt concrete, fibers have attracted the most attention due to their high and desirable characteristics. It is realized that the good distribution of the modifier in asphalt binder can generate a strong network in the interior structure of the blend, causing bitumen mastic to be more coherent. In this study, a laboratory investigation of the rheological and physical properties of various grades of bitumen modified by two types of fibers was conducted. Three grades of asphalt were used in this study (60-70 penetration grade, $80-100$ penetration grade and PG-76 grade) with two types of fibers with different percentages- Cellulose oil palm fiber (COPF) $(0.15,0.3,0.45,0.6$, and $0.75 \%)$ by weight of asphalt and carbon fiber $(0.75,1.25,1.75,2.25$, and $2.75 \%)$ by weight of asphalt. The results showed enhancement in physical performance of the modified bitumen in terms of the decrease in penetration values, as well as a rise in the softening point and viscosity values. The fibers' modified asphalt binders showed improved rheological properties and can raise the grade of asphalt depending on the base asphalt type.
\end{abstract}

Keywords: Carbon fiber; Cellulose oil palm fiber; Asphalt grade; Modified bitumen; Rheology.

\section{تأثثر أنواع مختلفة من الألياف على الخصائص الفيزيائية لارجات مختلفة من المثتبات الاسفلتية}

$$
\text { سعدي عبد نايه *، رنا عامر يو سف وقبس صاحب بني حسن }
$$

الملذص: منذ زمن بعيد كان ولا يز ال القار بستخذم كمادة أساسية في الرصف بالأسفلت. و لقد دفعت عدة عو امل مثل تقل الحمولة على المحور

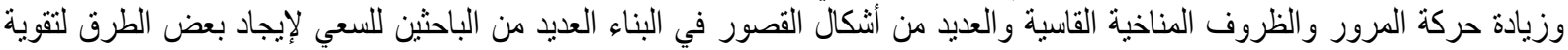

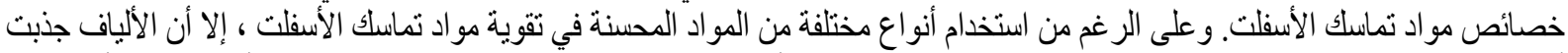

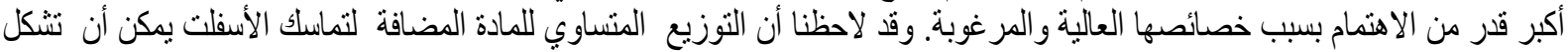

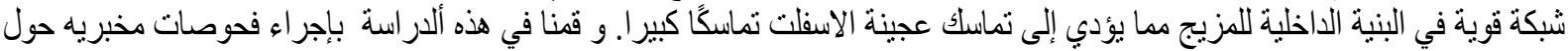

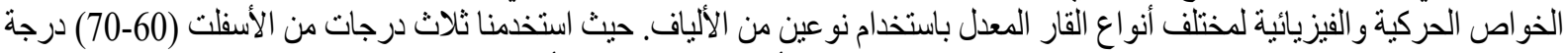

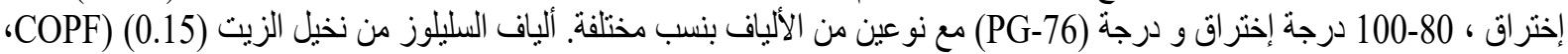

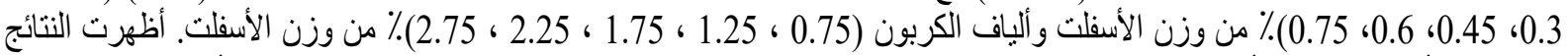

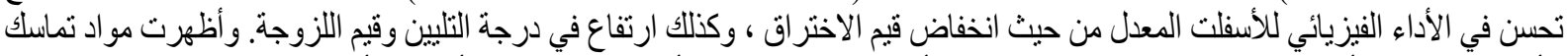

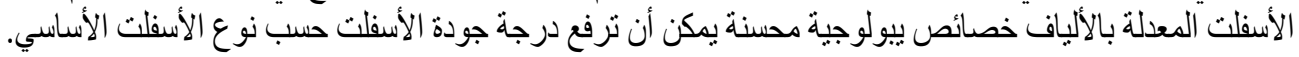

$$
\text { الكلمات الدفتاحية: ألياف الكربون؛ اليات السليلوز؛ نخيل الزيت؛ درجة الاسفلت؛ القار المعل؛ الخواص الحركية. }
$$

*Corresponding author’s e-mail: saabta75@yahoo.com 


\section{INTRODUCTION}

The continuous increase in axle loads, increase in traffic movement, critical environment circumstances, and failures in pavement construction as well as the an enormous increase in asphalt binder prices have justified endeavors of many researchers to seek some methods to enhance bitumen properties by producing higher viscosity low-priced asphalt for pavement construction. There is an extensive range of applications of bitumen modifiers in road construction (Muniandy et al., 2008).

Regarding the rise in the consumption of bitumen all over the globe, several experiments were conducted to boost the characteristics of such product. Besides the developments in the field of designing concept and applying asphalt pavement, these trials have led to using more suitable materials required for the construction of asphalt pavement. Such materials may be used straight as modifiers to strengthen or to enhance the fundamental components of bitumen (Airey, 2004).

\subsection{Carbon Fiber Modifier}

Many types of additives were utilized to maintain the phase composition and advance the engineering properties and supply more strength to asphalt pavement (Ahmedzade, 2013). Lately, the appliance of fibers, as a method for asphalt modification, has concerned many researchers. This is due to their intrinsic compatibility with bitumen and exceptional mechanical characteristics, as carbon fibers could supply a good promise for asphalt modification. Modifying asphalt mastic with carbon fiber is expected to increase stiffness and permanent deformation resistance as well as improving fatigue characteristics of the mixture. The cold service temperature behavior of carbon fiber-modified asphalt mixtures was expected to be boosted as well due to the high tensile strength of the carbon fiber (Cleven, 2000).

Nejad et al. (2014) conducted research utilizing carbon fiber to strengthen asphalt concrete. The outcomes showed that the use of carbon fibers in the asphalt concrete can noticeably improve the mechanical properties that benefit all the related fields involved issues like construction and maintenance.

Physical properties of various types of fibers and their enhancing and strengthening influence on bitumen mastic properties were studied by many researchers (Ling et al., 2014; Wu et al., 2015). Their results revealed that fibers can shape a three-dimensional space composition in bitumen that may transfer and buffer the applied loads. This network can offer a decrease in drain-down of asphalt binder from the mixture throughout forming a thicker mastic coating for aggregate particles. Fibers can efficiently enhance the rutting resistance of asphalt mastic.

\subsection{Cellulose Fiber Modifier}

The introduction of cellulose fibers, from annually renewable resources, is now a well-liked prevalence in the reinforcement of asphalt mastic. These offer advantages to the environment in relation to the degradability as well as utilization of materials from natural resources (Rout et al., 2001). Cellulose is respected as the main framework element of the fiber structure. The benefits of natural lingo-cellulosic fibers over conventional strengthening materials are the satisfactory mechanical properties, low price, low density, suitable thermal properties, non-abrasivity, and improved energy salvage (Doan et al., 2006; Abiola et al., 2014).

There are some researches that has attempted to investigate the potential of cellulose fibers to bolster asphalt binder. Kumar et al. (2004) studied the modification of SMA with two types of fibers, jute and synthetic. Jute fiber SMA mixtures showed better permanent deformation and higher creep modulus than synthetic fibers SMA mixtures. Yang et al. (2006) investigated the resistance to deformation resistance of cellulose and polyester fibers modified bitumen. The achieved results displayed the significant improvement of the rut resistance. However, polyester fibers were relatively better regarding the rutting resistance than cellulose fibers samples do.

Some researchers evaluated the influence of date palm and textile fibers on open graded course mixture characteristics. The results have shown that the utilization of fibers in the asphalt mixture led to a considerable decrease in drain-down contrasted to other types of modified mixtures (Hassan and AlJabri, 2005; Sharma and Goyal, 2006). Muniandy and Huat (2010) used Cellulose fiber extracted from oil palm bunch to study the rheological performance of asphalt binders. The tests have shown the base binder (PG64-22) could be upgraded to PG70-22 grade as well as improving the fatigue performance of SMA mixture. The optimum cellulose fiber to be introduced to the base bitumen was found to be $0.6 \%$. Another research conducted by Muniandy et al. (2008) dealt with the advantage of the Date Empty Fruit Bunch (DEFB) and Oil Palm trees to generate cellulose fiber to be used as additives in the bitumen. The outcomes showed that the used fibers improved the rheological properties of the asphalt mastic by increasing the PG grading two steps from PG58 to be PG70 at $0.3 \%$ oil palm cellulose fiber concentration.

Other researchers have attempted to study the influence of several cellulose fiber types and percentages on rheological and physical rheological properties of bitumen. The cellulose fiber modified bitumen displayed an increase in viscosity and softening point values as well as a reduction in penetration with increasing cellulose fiber content. The rheological tests showed an improvement in rutting resistance and fatigue cracking (Maniruzzaman et al., 2015a; Maniruzzaman et al., 2015b; Al-Otaibi et al., 2016; Bonica et al., 2016). According to the literature stated above, the 
application of fibers and tire crumb rubber in asphalt may enhance the mechanical behavior represented by fatigue performance, strength, and Marshall Stability. However, for comparative purposes, the extent of the effect of each type of modifiers and their optimum proportion of adding them to the base asphalt cement have a big influence on the implementation of bitumen. So, the major objective of this study is to realize the best additive amongst them and the best percentage for strengthening bitumen mortar throughout a series of tests on the rheological and physical properties of the modified and unmodified bitumens. To this end, cellulose oil palm fiber, carbon fibers, and tire crumb rubber with different proportions by weight of the binder are added to three types of binders $(80 / 100,60 / 70$, and PG75) to be tested and evaluated.

\section{MATERIALS AND METHODS}

\subsection{Asphalt Binders}

Traditionally the $80 / 100$ binder is incapable of opposing the heavy weights from different trucks because it does not have a suitable fatigue and rutting performance. The use of modifiers such as crumb rubber and fibers may improve the service properties of the asphalt mastic by different mechanisms. Therefore, for the purpose of investigating the effect different additives on different grade asphalt binders, three grades of asphalt were used as base asphalt binders (80-100 and 60-70 penetration grade asphalts as well as PG-76 performance grade asphalt). The laboratory assessments were conducted in order to estimate the binders' properties for penetration, softening point, viscosity, specific gravity, and ductility. Table 1 shows the physical properties of the three base binders used in this study.

\subsection{Additives}

Two types of additives were used in this study:

2.2.1 Carbon Fiber: The physical properties of carbon fiber employed in this research are summarized in Table 2.

2.2.2. Cellulose Oil Palm Fiber (COPF): The oil palm bunches were collected from a plantation area then cut into small pieces. The cellulose oil palm fibers were made by chemical-R of pulping method. The oil palm fibers used are with a moisture content of about $5 \%$ and a cellulose content of at least $75 \%$ and a $\mathrm{pH}$ of $7 \pm 5 \%$. The ash content is $3.5 \%$ and the density is about $1.5 \mathrm{~g} / \mathrm{cm}^{3}$. The cellulose oil palm fiber size distributions are presented in Table 3.

\subsection{Preparation of modifier-asphalt mastic}

Modified asphalt binder specimens were made according to standard techniques employed and published in several journal researches. All the prepared samples were derived from the same neat asphalt binder sources.

Two kinds of fibers (cellulose oil palm fiber, and carbon fibers) were used as modifier. A high shear mixer was used to achieve an excellent distribution of fibers into the base binders with a revolution of about $1000 \mathrm{rpm}$. The fibers were discretely placed into the oven at $105^{\circ} \mathrm{C}$ for $24 \mathrm{~h}$ to make sure that the least moisture, and a $500 \mathrm{~g}$ sample of bitumen were put into a container and heated at $160^{\circ} \mathrm{C}$ for $30 \mathrm{~min}$ to soften it prior to blending. To explore the effect of fibers on bitumen mortar, various fiber proportions in the asphalt mortars were added. The cellulose fibers (COPF) contents used were $(0.15,0.3,0.45,0.6$ and $0.75 \%$ ) by weight of asphalt, while the carbon fiber contents used were $(0.75,1.25,1.75,2.25 \& 2.75 \%)$ by weight of asphalt. Blending then continued at $160^{\circ} \mathrm{C}$ for $30 \mathrm{~min}$ to provide a homogeneous blend. In order to prevent the contrary influence of extreme heating, the temperature was cautiously observed using a thermometer with a thermocouple probe. After completion, the modified binder was extracted from the metal tins and separated into small containers enclosed by aluminum foil then kept for further testing at room temperature.

\section{RESULTS AND DISCUSSION}

\subsection{Conventional tests}

The traditional tests, like penetration (ASTM D5), softening point (ASTM D36) and viscosity (ASTM D4402), were first conducted for the neat binders and then for modified binders according to standards.

3.1.1 Penetration test: Figs. 1 and 2 show penetration test results for neat and modified asphalt binders. From this figure, it can be noticed that, with the increase in the percentage of modifiers, the value of penetration decreases. On the other hand, the figures show that cellulose fiber modified binders have higher values of penetration as compared with carbon fiber asphalt binder samples. The penetration value of the modified high-quality binder samples (PG76) did not change significantly.

Table 1. Physical Properties of Asphalt Cement.

\begin{tabular}{|c|c|c|c|c|}
\hline Binder properties & Specification & $80-100$ & PG-76 & $60-70$ \\
\hline $\begin{array}{l}\text { Penetration }\left(25^{\circ} \mathrm{C} \text {, }\right. \\
100 \mathrm{gm}, 5 \mathrm{sec} .) \\
(0.1 \mathrm{~mm})\end{array}$ & ASTM D5 & 84 & 33.5 & 63.5 \\
\hline $\begin{array}{l}\text { Softening point (ring } \\
\& \text { ball) }{ }^{\circ} \mathrm{C}\end{array}$ & ASTM D36 & 46.5 & 73.5 & 49 \\
\hline $\begin{array}{l}\text { Viscosity at } 135^{\circ} \mathrm{C} \\
\text { (cP) }\end{array}$ & ASTM D4402 & 297.45 & 1541.8 & 382.3 \\
\hline $\begin{array}{l}\text { Ductility }\left(25^{\circ} \mathrm{C} \text {, }\right. \\
5 \mathrm{~cm} / \mathrm{min}) .\end{array}$ & ASTM D113 & $>100$ & $>100$ & $>100$ \\
\hline $\begin{array}{l}\text { Specific gravity at } \\
25^{\circ} \mathrm{C}\left(\mathrm{g} / \mathrm{cm}^{3}\right)\end{array}$ & ASTM D70 & 1.036 & 1.03 & 1.04 \\
\hline
\end{tabular}


Table 2. Physical Properties of Carbon Fiber.

\begin{tabular}{lll} 
Source & $\begin{array}{l}\text { 100\% carbon fiber } \\
\text { from Japan }\end{array}$ & $\begin{array}{l}\text { Tensile strength } \\
(\mathrm{GPa})\end{array}$ \\
\hline Yarn type & 12K carbon fiber & $\begin{array}{l}\text { Tensile Modulus } 230 \\
(\mathrm{GPa})\end{array}$ \\
$\begin{array}{l}\text { Chopped } \\
\text { length }(\mu \mathrm{m})\end{array}$ & 150 & $\begin{array}{l}\text { Carbon content } \geq 95 \\
(\%)\end{array}$ \\
$\begin{array}{l}\text { Filament } \\
\text { diameter }(\mu \mathrm{m})\end{array}$ & 7.0 & Density $(\mathrm{g} / \mathrm{cm} 3) \quad 1.76$ \\
\hline
\end{tabular}

Table 3. Cellulose Oil Palm Fiber Size Distribution.

\begin{tabular}{lcc}
\hline No. & Sieve size $(\mu \mathrm{m})$ & \% Passing \\
\hline 1 & 580 & 90 \\
2 & 425 & 80 \\
3 & 250 & 65 \\
4 & 180 & 55 \\
5 & 150 & 35 \\
6 & 106 & 20 \\
\hline
\end{tabular}

Table 4. The Maximum Allowable Percentage of Additives to Each Base Binder Type.

\begin{tabular}{ccc}
\hline Additive Type & Binder Type & Max. Additive \% \\
\hline \multirow{2}{*}{ Carbone Fiber } & $80-100$ & 1.75 \\
& $60-70$ & 1.35 \\
& PG76 & 1.1 \\
Cellulose Fiber & $80-100$ & 0.28 \\
& $60-70$ & 0.23 \\
& PG76 & 0.1 \\
\hline
\end{tabular}

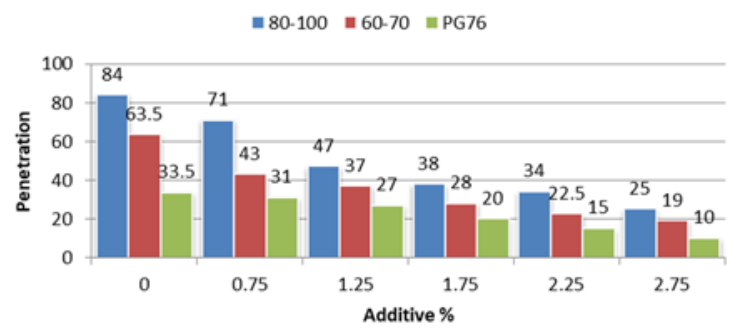

Figure 1. Effect of Carbon Fiber Content on Penetration for Asphalt Binders.

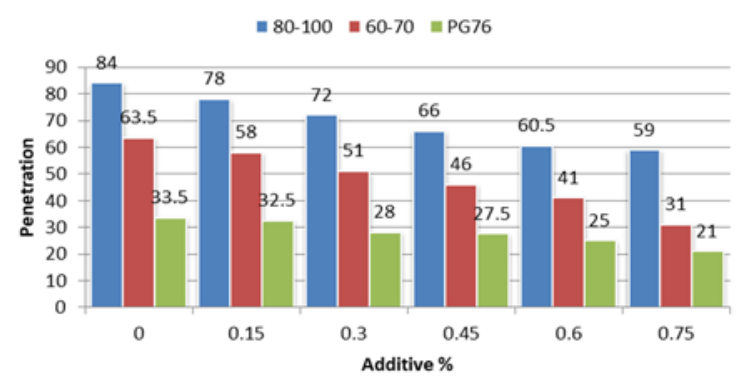

Figure 2. Effect of Cellulose Fiber Content on Penetration for Asphalt Binders.

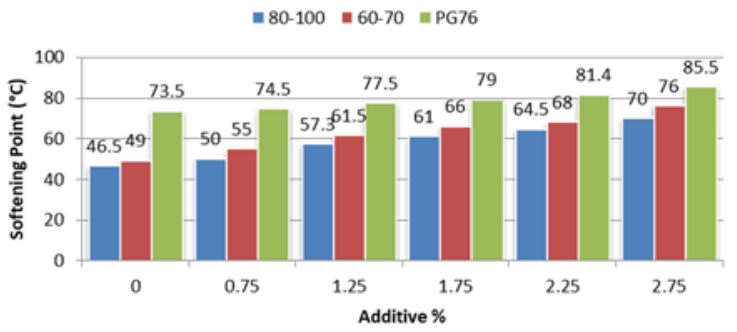

Figure 3. Effect of Carbon Fiber Content on Softening Point for Asphalt Binders.

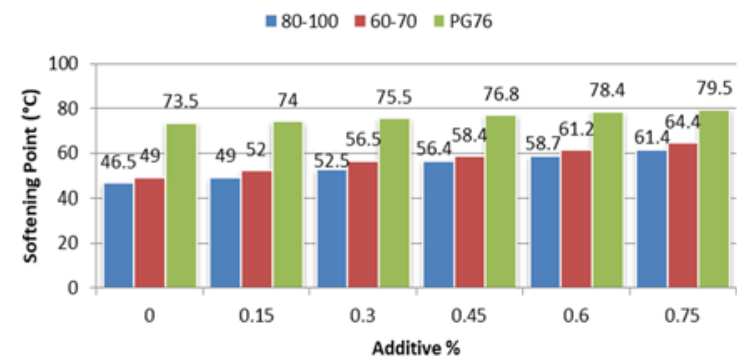

Figure 4. Effect of Cellulose Fiber Content on Softening Point for Asphalt Binders.

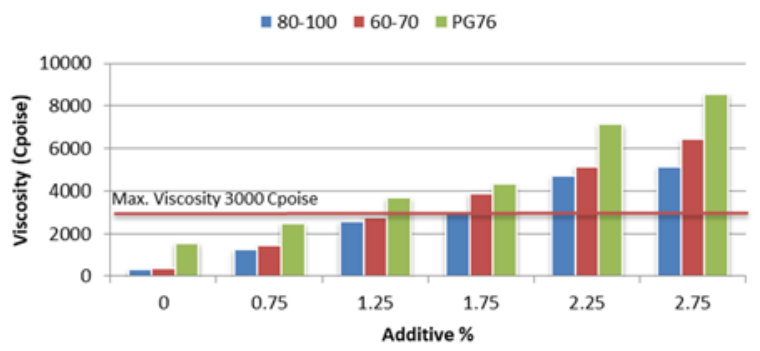

Figure 5. Effect of Carbon Fiber Content on Viscosity for Asphalt Binders.

$=80-100=60-70=\mathrm{PG} 76$

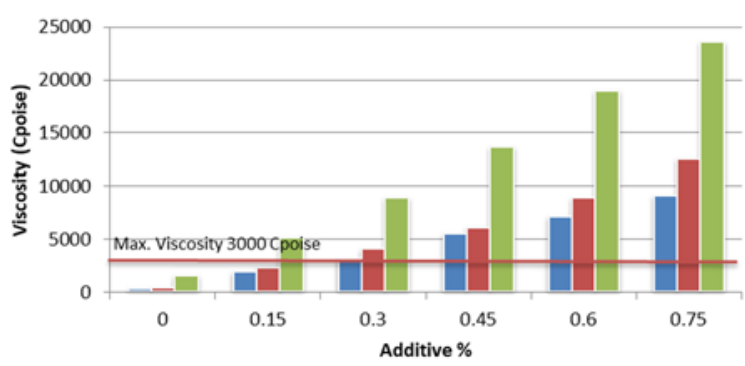

Figure 6. Effect of Cellulose Fiber Content on Viscosity for Asphalt Binders.

3.1.2. Softening point test: The outcomes of the softening point test for the three types of binders and two types of fibers are shown in Figures 3 and 4. It can be seen, as opposed to the penetration measurements, with increasing the fiber percentage, the softening point increased. There were somewhat significant changes in softening point values liable on the sort of the base binder. However, the softening point values for the high-quality asphalt binder (PG76) modified by 
the two fiber types did not change significantly.

3.1.3. Viscosity tests: Figures 5 and 6 show the viscosity values of the control and modified bitumen. The viscosity values of the fiber modified bitumen are greater than the base bitumen. The more modifiers are introduced into the base bitumen, the greater viscosity values are gained. Some viscosity values of the fiber modified asphalt binders were higher than 3 Pa.s, and so didn't fulfill the requirement standard of Superpave ${ }^{\mathrm{TM}}$. Based on that, the recommended proportions to add each additive to each of the three base binders used in this study were estimated and presented in Table 4 . The viscosity value is a crucial issue for transportation of bitumen. Excessively high value of viscosity is unfavorable when transporting bitumen using pipelines. Thus, over-viscous bitumens are inappropriate for use in pavement industry.

Based on the previous outcomes, the introduction of the two fibers into the base asphalt binders enhances the physical properties of the modified bitumen binders as indicated by the reduction in penetration value and increase in softening point, and an increase in the viscosity values, thus enhancing modified binder stiffness and increasing its capability to resist rutting deformation.

\subsection{Rheological properties for modified asphalt binder}

The dynamic rheological characteristics of the cellulose modified asphalt mastic were determined utilizing a dynamic shear rheometer (DSR, HAAKE, Rheo Stress RS1, Phoenix) throughout an extensive extent of temperatures to illustrate both viscous and elastic behaviors of unaged modified binders. Two $25 \mathrm{~mm}$ diameter parallel plates with a gap of $1 \mathrm{~mm}$ were determined to do the DSR measurements. A constant sinusoidal stress of $0.12 \mathrm{kPa}$ was directed at low strain to keep all the tests performed within the linear viscoelastic limit. The real strain and rotation were measured for determining viscoelastic factors, counting complex modulus $\left(\mathrm{G}^{*}\right)$ and phase angle $(\delta)$. Furthermore, the rutting factor $\left(\mathrm{G}^{*} / \sin \delta\right)$ was utilized to primarily measure the rutting resistance and stiffness of the asphalt mastics (Yi-qiu et al., 2010).

\subsubsection{Temperature sweep test at high temperature:}

The fundamental rheological properties of the neat asphalt and modified bitumens, cellulose fibers (COPF) and carbon fiber by temperature sweep test at un-aged state using dynamic shear rheometers (DSR). A DSR oscillation temperature sweep test was performed at intermediate and high temperatures that ranged from 40 to $82^{\circ} \mathrm{C}$ with a 6-degree step to determine the change in binder performance as a function of temperature and $10 \mathrm{rad} / \mathrm{s}(1.59 \mathrm{~Hz})$ frequency. A minimum value of $1.0 \mathrm{kPa}$ for $\mathrm{G}^{*} / \sin \delta$ is recommended to ensure that asphalt binder could resist well against permanent deformation at the designed performance grade temperature. The minimum limit for $\mathrm{G}^{*} / \sin \delta$ is $1000 \mathrm{~Pa}$ for an unaged asphalt binder.
Figs. 7 and 12 present the relation between the rutting factor and temperature during temperature sweep test showing the failure temperatures for the two types of modified binders.

The cellulose modified bitumens have greater values of rutting factor than the control bitumens. Consistent with the specification, these modified bitumens have a reduced rutting susceptibility, especially at high service temperature contrasted to the base binders. From Table 5, it can be seen that the failure temperatures of the modified asphalt binders are greater than the base asphalt binders. As a result, the high-temperature grade $(\mathrm{PG})$ for the base binders has been increased.

The addition of the two fiber types into the base bitumens caused them to be stiffer. Greater $G^{*}$ and $\mathrm{G}^{*} / \sin \delta$ of these modified bitumens show that the bitumen could sustain additional energy when loading is directed, and similarly, they reveal that the modified binders have better resistance to rutting and fatigue cracking under intermediate and high service temperatures. The asphalt binders modified with carbon fiber mostly have similar resistance to rutting, which are clearly better than the control bitumens. At the same time, the base binder PG76 was the highest in terms of rutting resistance and stiffness followed by $60 / 70$ and $80 / 100$ binders respectively. So, the control binder source has a great impact on the rutting parameter values of various binders in this research. It can be evidently seen that the unmodified binders are categorized as PG58, PG64, and PG76, respectively. Coming back to the maximum failure percent of each additive to each control asphalt type according to the viscosity test results, the addition of 1.75 and $1.35 \%$ carbon fiber to $80-100$ and 60-70 asphalt binders, respectively, had enhanced the PG grading two steps for 80-100 binder from PG58 to PG70, and enhanced PG grading one step from PG64 to PG70, while the effect of adding $1.1 \%$ of carbon fiber to PG76 binder did not change the PG grading significantly. The same trend is occurring with the addition of cellulose fiber to the three base binders, with slight differences. The addition of 0.28 and $0.23 \%$ cellulose fiber to $80-100$ and 60-70 asphalt binders, respectively, had enhanced the PG grading two steps for 80-100 binder from PG58 to PG70 and enhanced PG grading one step from PG64 to PG70, while the effect of adding $0.1 \%$ of cellulose fiber to PG76 binder did not change the PG grading significantly.

\section{CONCLUSION}

In this paper, the effects of adding cellulose oil palm fiber, and carbon fiber to three asphalt binder types were studied. There are several conclusions derived from the results:

- The two modifiers are well dispersed in the asphalt, due to the fact that no blocks or agglomerates can be seen after the 
blending process.

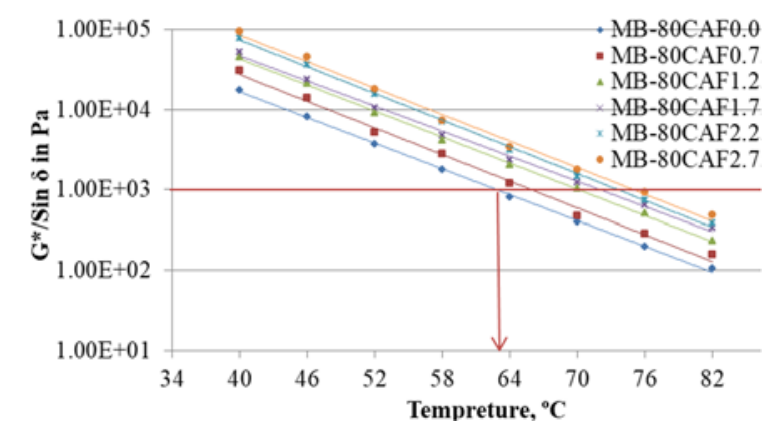

Figure 7. Temperature Sweep Test for 80-100 Asphalt Binder Modified with Carbon Fiber.

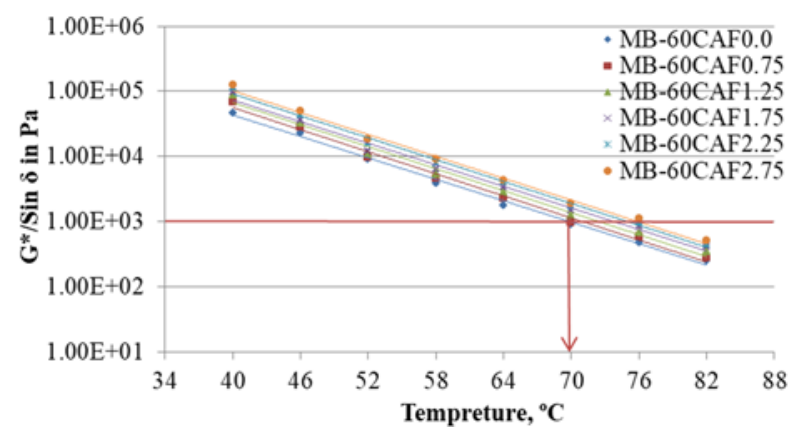

Figure 8. Temperature Sweep Test for 60-70 Asphalt Binder Modified with Carbon Fiber.

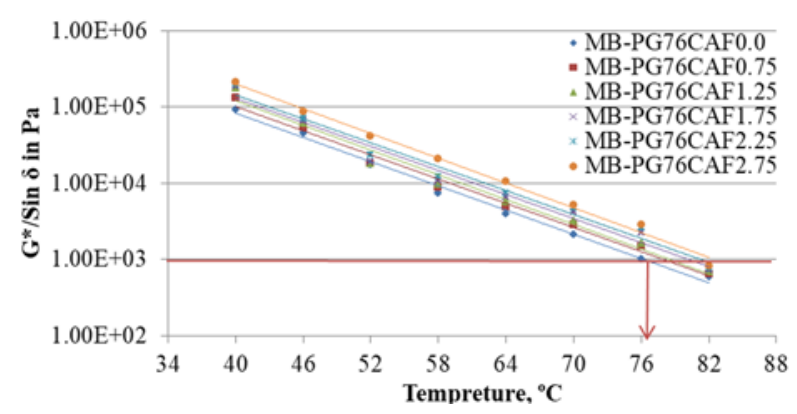

Figure 9. Temperature Sweep Test for PG76 Asphalt Binder Modified with Carbon Fiber.

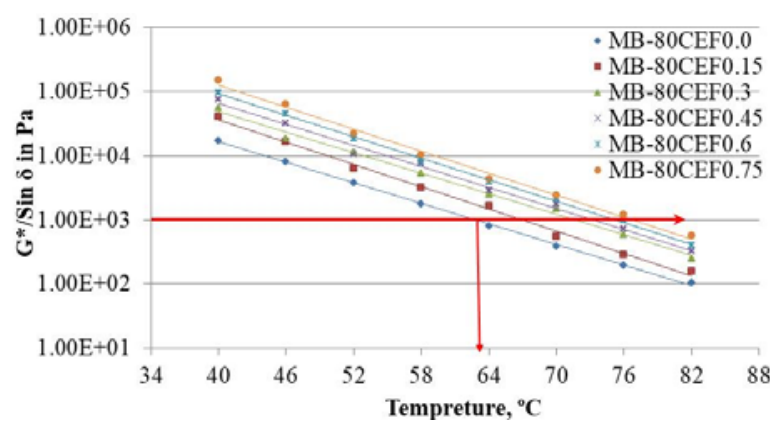

Figure 10. Temperature Sweep Test for 80-100 Asphalt Binder Modified with Cellulose Fiber.

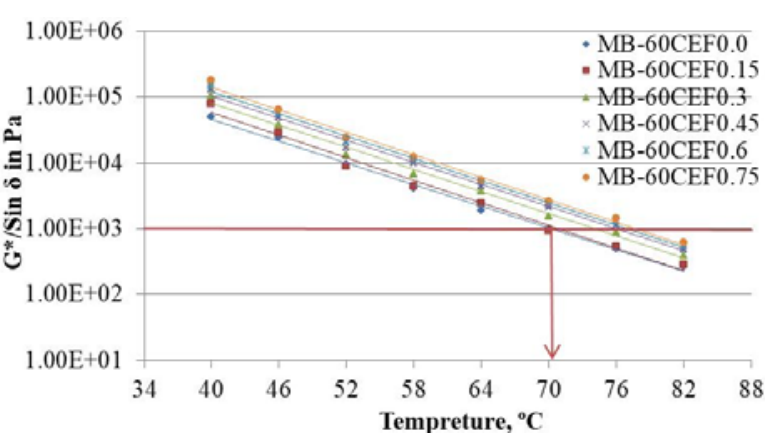

Figure 11. Temperature Sweep Test for 60-70 Asphalt Binder Modified with Cellulose Fiber.

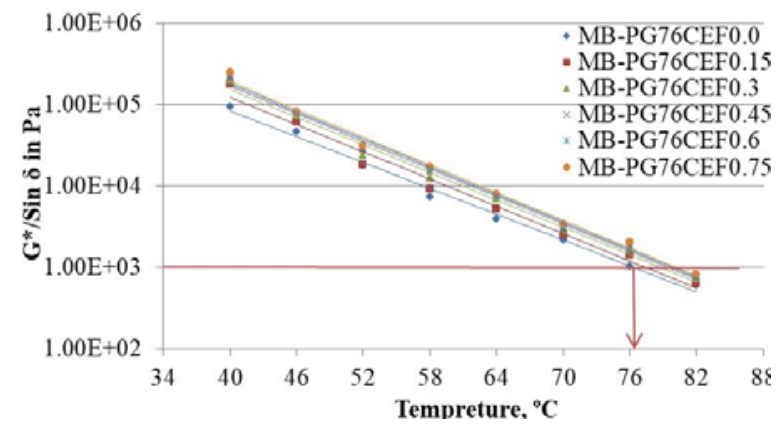

Figure 12. Temperature Sweep Test for PG76 Asphalt Binder Modified with Cellulose Fiber.

Table 5. Failure Temperature of the Modified Binders.

\begin{tabular}{lllllll}
\hline \multicolumn{7}{c}{ Carbon Fiber \% } \\
\hline Binder Type & 0 & 0.75 & 1.25 & 1.75 & 2.25 & 2.75 \\
S0-100 & 62.8 & 66.3 & 70.8 & 72.3 & 74 & 75.2 \\
$\mathbf{6 0 - 7 0}$ & 69.5 & 70.6 & 72.2 & 73.8 & 75.5 & 76 \\
PG76 & 76.5 & 78 & 78.8 & 80.3 & 81.5 & 82.2 \\
\cline { 2 - 7 } & \multicolumn{7}{l}{ Cellulose Fiber \% } & & & \\
\cline { 2 - 7 } Binder Type & 0 & 0.15 & 0.3 & 0.45 & 0.6 & 0.75 \\
80-100 & 62.8 & 66.5 & 71.5 & 73.3 & 75 & 77 \\
$\mathbf{6 0 - 7 0}$ & 69.5 & 70.8 & 74 & 76 & 77.3 & 78 \\
PG76 & 76.5 & 77.5 & 79 & 79.2 & 80 & 80.2 \\
\hline
\end{tabular}

- The addition of carbon fiber and cellulose fibers to the asphalt binder improves the physical properties of the base asphalt binders as indicated by the decrease in penetration value and rise in softening point temperatures.

- The introduction of the two modifiers into base asphalt binders can considerably improve the viscosity of the bitumen, which is helpful to enhance the high temperature performance of asphalt binders. Cellulose and carbon fibers displayed very high viscosity values when added at high percentages to the base asphalt binders that exceed the specification requirement of $3 \mathrm{~Pa} . \mathrm{s}$ at $135^{\circ} \mathrm{C}$.

- Cellulose fibers have the most significant enhancement to viscosity and rutting factor of asphalt binders as compared with carbon fibers.

- Asphalt cement source may influence the behavior 
of the modified mastic in different ways.

- The quality of the base asphalt binder is a crucial factor. Higher quality base asphalt binder showed little enhancements (PG76), whereas the lowest quality binders exhibit considerable enhancement in the conducted tests (80-100 and 60-70 binders).

- The DSR tests presented that fiber modified bitumen mastics have higher rutting parameters $\left(\mathrm{G}^{*} / \sin \delta\right)$ contrasted by with the base bitumen mastics employed in this research. Thus, fibers can significantly enhance asphalt mastic flow.

\section{CONFLICT OF INTEREST}

The authors declare no conflicts of interest.

\section{FUNDING}

No funding was received for this project.

\section{ACKNOWLEDGMENT}

We would like to express our thanks and gratitude to all those who contributed to this modest work, especially the technical staff of the asphalt technology laboratory at the University of Putra, Malaysia, as well as the Central Transport Laboratory at the Faculty of Engineering, Mustansiriya University.

\section{REFERENCES}

Abiola OS, Kupolati WK, Sadiku ER, and Ndambuki JM (2014), Utilisation of natural fibre as modifier in bituminous mixes: A review. Construction and Building Materials 54: 305-312.

Ahmedzade P (2013), The investigation and comparison effects of SBS and SBS with new reactive terpolymer. Construction and Building Materials 38:285-291.

Airey GD (2004), Fundamental binder and practical mixture evaluation of polymer modified bituminous materials. International Journal of Pavement Engineering 5(3): 137-151.

Al-Otaibi HM, Al-Suhaibani AS, and Alsoliman HA (2016), Physical and Rheological Properties of Asphalt Modified with Cellulose Date Palm Fibers. World Academy of Science, Engineering and Technology, International Journal of Civil, Environmental, Structural, Construction and Architectural Engineering 10(5): 583-587.

Bonica C, Toraldo E, Andena L, Marano C, and Mariani E (2016), The effects of fibers on the performance of bituminous mastics for road pavements. Composites Part B: Engineering 95: 76-81.

Cleven M.A. (2000), "Investigation of the properties of Carbon Fiber Modified Asphalt Mixtures," Master thesis, Michigan Technological University,
Mishigan.

Doan TTL, Gao SL, and Mäder E (2006), Jute/polypropylene composites I. Effect of matrix modification. Composites Science and Technology 66(7-8): 952-963.

Hassan HF, and Al-Jabri KS (2005), Effect of organic fibers on open-graded friction course mixture properties. International Journal of Pavement Engineering 6(1): 67-75.

Kumar P, Sikdar PK, Bose S, and Chandra S (2004), Use of jute fibre in stone matrix asphalt. Road materials and pavement design 5(2): 239-249.

Ling PA, Peng WA, Bo LI, Pan PA, and Shaopeng WU (2014), Investigation of Rheological Characteristics of Carbon fiber Modified Asphalt Binder. Key Engineering Materials 599.

Maniruzzaman AM, Hamad AW, Maleka AM, and Elsergany M (2015a), Rheological Properties of Cellulose Oil Palm Fiber (COPF) Modified 80100 Asphalt Binder. Journal of Advanced Research in Materials Science 5(1): 10-20.

Maniruzzaman AM, Hamad AW, Maleka AM, Jakarni FM, and Bahru UJ (2015b), Effect of Viscoelastic Behavior of Cellulose Oil Palm Fiber (COPF) Modified 60-70 Asphalt Binder for Deterioration for Roads and Highways. Jurnal Teknologi 75(11): 17-23.

Muniandy R, and Huat BB (2006), Laboratory diameteral fatigue performance of stone matrix asphalt with cellulose oil palm fiber. American Journal of Applied Sciences 3(9): 2005-2010.

Muniandy R, Jafariahangari H, Yunus R, and Hassim $\mathrm{S}$ (2008), Determination of rheological properties of bio mastic asphalt. American Journal of Engineering and Applied Sciences 1(3): 204-209.

Nejad FM, Vadood M, and Baeetabar S (2014), Investigating the mechanical properties of carbon fibre-reinforced asphalt concrete. Road Materials and Pavement Design 15(2): 465-475.

Rout J, Misra M, Tripathy SS, Nayak SK, and Mohanty AK (2001), The influence of fibre treatment on the performance of coir-polyester composites. Composites Science and Technology 61(9): 1303-1310.

Sharma V, and Goyal S (2006), Comparative study of performance of natural fibres and crumb rubber modified stone matrix asphalt mixtures. Canadian Journal of Civil Engineering 33(2): 134-139.

Wu MM, Li R, Zhang YZ, Fan L, Lv YC, and Wei JM (2015), Stabilizing and reinforcing effects of different fibers on asphalt mortar performance. Petroleum Science 12(1): 189-196.

Yang J, Shi X, Wan J, Qian G, Pan W, and Yang Y (2006), Evaluation of rutting resistance of doublelayered asphalt mixes. Road Materials and Pavement Design 7: 533-542.

Yi-qiu T, Li X, and Zhou X (2010), Interactions of granite and asphalt based on the rheological characteristics. Journal of Materials in Civil Engineering 22(8): 820-825. 